\title{
Classifying Inputs and Outputs with Fuzzy Data
}

\author{
Mehrdad Nabahat ${ }^{1}$ \& Fardin Esmaeeli Sangari $^{1}$ \\ ${ }^{1}$ Sama Technical and Vocational Training School, Islamic Azad University, Urmia branch Urmia, Iran \\ Correspondence: Mehrdad Nabahat, Sama Technical and Vocational Training School, Islamic Azad University, Ur- \\ mia branch Urmia, Iran. E-mail: m_nteach2009@yahoo.com; Fardin Esmaeeli Sangari, E-mail: \\ Fardin_e_s@yahoo.com
}

Received: May 13, 2012 Accepted: May 30, 2012 Online Published: July 10, 2012

doi:10.5539/jmr.v4n4p46 URL: http://dx.doi.org/10.5539/jmr.v4n4p46

\begin{abstract}
Data envelopment analysis is a nonparametric technique checking efficiency of DMUs using math programming. In conventional DEA, it has been assumed that the status of each measure is clearly known as either input or output. However in some situations, a performance measure can play input role for some DMUs and output role for others. There are different models for classifying inputs and outputs, but all of these models are with crisp data. In this paper we want to classify inputs and outputs when all of the DMUs have symmetrical triangular fuzzy inputs and outputs and flexible measures. The basic idea is to transform the fuzzy model into a crisp linear programming problem by applying an $\alpha$-cut approach.Finally, a numerical example is proposed to display the application of this method.
\end{abstract}

Keywords: Data Envelopment Analysis, flexible measure, linear programming, possibilistic linear programming, symmetrical triangular fuzzy number

\section{Introduction}

DEA is a powerful tool in estimating efficiency of decision making units with multiple inputs and outputs. Charnes, Cooper and Rhodes (1978, p. 429-444) were the pioneers of the field that introduced their first model named "CCR" in 1978. The assumption is that all the data have specific numerical values. In some application, however, the data may be imprecise. DEA is an effective technique for measuring the relative efficiency of a set of homogeneous DMUs. In conventional DEA applications, it is assumed that the status of each measure is clearly known that used as an input or output variable.

Cook and Zhu (2007, p. 692-699) considered variables whose status are flexible and proposed a different method for classifying these variables by introducing a fractional programming problem to accommodate flexible measures. Amirteimoori and Emrouznejad (2011, p. 63-74) proposed a model in which flexible measures are axiomatically imported in a mixed integer linear programming model. Amirteimoori and Khoshandam (2011, p. 267) proposed a model in which each flexible measure is treated as either input or output to maximize the technical efficiency of the DMU under evaluation. The assumption is that all the data have specific numerical value. In some cases the data may be imprecise.

Only a few researches have utilized fuzzy set theory to measure and evaluate efficiency performance. Sengupta (1992, p. 259-266) was the first to introduce a fuzzy mathematical programming approach where the constraints and objective function are not satisfied crisply. Fuzzy DEA models can more realistically represent real world problems than the conventional DEA models. We can consider two approaches for solving fuzzy CCR. The first one defuzzifies the fuzzy CCR model and changed it into the equivalent crisp model and the second one uses $\alpha$-cuts to create interval valued linear programming that solves the fuzzy DEA by parametric programming. Tananka, Entani and Maeda (1998, p. 1067-1071), formulated two DEA models: one model that gives upper limit (best case) efficiency and one model that gives lower limit (worse case) efficiency. With defuzzification approach we first defuzzify the fuzzy inputs and outputs into crisp values, and then solve the resulting crisp model using an LP solver. Guo and Tanaka (2011, p. 149-160) considered the data as symmetrical triangular fuzzy vectors in fuzzy DEA model. In the most fuzzy CCR model after determining the $\alpha$-cuts of objective function and constraints, the fuzzy triangular numbers are converted to crisp intervals. In most of the existing methods for possibilistic linear programming, where the $\alpha$-cut is used, the solution is obtained by comparing the intervals in left and right hand side of constraints Shaocheng (1994, p. 301-306), Tanaka, Ichihashi and Asai (1984, p. 186-194). Different 
methodologies have been suggested for comparison of the intervals. In some of these methods simply the end point of the interval are considered for justification that makes the model very simple and hence a lot of information might have been lost. Saati and Memariani and Jahanshahloo (2002, p. 255-267), their method is to find a point in each interval, satisfying the set of constraints and at the same time maximizing the objective function. This is defined as a variable in the suggested method. In this paper we want to classify the inputs and outputs with fuzzy data and evaluate the efficiency of DMUs with fuzzy inputs and outputs and fuzzy flexible measures. We convert the fuzzy linear programming to interval linear programming by $\alpha$-cut method.

\section{Fuzzy Model}

Assume that there are $\mathrm{n}$ decision-making units (DMUs) to be evaluated, each DMU with $m$ inputs and $s$ outputs and $t$ flexible measures. We denote the inputs and outputs and flexible measure of $D M U_{j}: j=1, \ldots, n$ respectively with $x_{i j}: i=1, \ldots, m$ and $y_{r j}: r=1, \ldots, s$ and $z_{k j}: k=1, \ldots, t$. These flexible measure status are unknown, some DMUs may use this measures as inputs and other DMUs may use them as outputs.The model which proposed by Amirteimoori is shown as follows:

$$
\begin{aligned}
& \operatorname{Min} \sum_{i=1}^{m} s_{i}+\sum_{r=1}^{s} d_{r}+\sum_{k=1}^{t} g_{k} \\
& \sum_{j=1}^{n} \lambda_{j} x_{i j}+s_{i}=x_{i o}, i=1, \ldots, m \\
& \sum_{j=1}^{n} \lambda_{j} y_{r j}-d_{r}=y_{r o}, r=1, \ldots, s \\
& \sum_{j=1}^{n} \lambda_{j} z_{k j}-g_{k}=z_{k o}, k=1, \ldots, s \\
& s_{i}, d_{r}, \lambda_{j} \geq 0, \forall i, r, j, g_{k} \text { isfree }
\end{aligned}
$$

The dual formulation of (1) is as follows:

$$
\begin{aligned}
& \operatorname{Max} \sum_{r=1}^{s} u_{r} y_{r o}-\sum_{i=1}^{m} v_{i} x_{i o}-\sum_{k=1}^{t} \mu_{k} z_{k o} \\
& \sum_{r=1}^{s} u_{r} y_{r j}-\sum_{i=1}^{m} v_{i} x_{i j}-\sum_{k=1}^{t} \mu_{k} z_{k j} \leq 0, j=1, \ldots, n, \\
& u_{r} \geq 1, r=1, \ldots, s, \quad v_{i} \geq 1, i=1, \ldots, m \\
& \mu_{k}=1, \quad k=1, \ldots, t
\end{aligned}
$$

In model (1) $g_{k}$ is unrestricted in sign. When $g_{k}>0$ this means that $z_{k o}$ is considered as input and in opposite side, if $g_{k}<0$ this means that $z_{k o}$ is considered as output. $g_{k}=0$ means that $z_{k o}$ can play input or output role.

Now we consider that all of the inputs and outputs and flexible measures of DMUs are triangular fuzzy numbers. Let $\tilde{x}_{i j}=\left(x_{i j}^{m}, x_{i j}^{l}, x_{i j}^{u}\right)$ and $\tilde{y}_{r j}=\left(y_{r j}^{m}, y_{r j}^{l}, y_{r j}^{u}\right)$ and $\tilde{z}_{k j}=\left(z_{k j}^{m}, z_{k j}^{l}, z_{k j}^{u}\right)$. which $\left(\cdot{ }^{l}\right)$ and $\left(\cdot{ }^{u}\right)$ respectively indicates the lower bound and upper bound of fuzzy numbers. Therefore, (2) can be written as follows:

$$
\begin{aligned}
& \operatorname{Max} \sum_{r=1}^{s} u_{r}\left(y_{r o}^{m}, y_{r o}^{l}, y_{r o}^{u}\right)-\sum_{i=1}^{m} v_{i}\left(x_{i o}^{m}, x_{i o}^{l}, x_{i o}^{u}\right)-\sum_{k=1}^{t} \mu_{k}\left(z_{k o}^{m}, z_{k o}^{l}, z_{k o}^{u}\right) \\
& \sum_{r=1}^{s} u_{r}\left(y_{r j}^{m}, y_{r j}^{l}, y_{r j}^{u}\right)-\sum_{i=1}^{m}\left(x_{i j}^{m}, x_{i j}^{l}, x_{i j}^{u}\right)-\sum_{k=1}^{t} \mu_{k}\left(z_{k j}^{m}, z_{k j}^{l}, z_{k j}^{u}\right) \leq 0, j=1, \ldots, n, \\
& u_{r} \geq 1, r=1, \ldots, s, \quad v_{i} \geq 1, i=1, \ldots, n, \\
& \mu_{k}=1, \quad k=1, \ldots, t
\end{aligned}
$$

Model (3) is a possibilistic linear programming. By using different $\alpha$-cuts the model is transformed to intervalprogramming problem. There are many methods for solving interval-programming problem but we use Saati and memariani method, which instead of comparing the intervals, they define variables in the intervals such that they satisfy the set of constraints and at the same time the objective function is maximized to solve the problem. Considering different $\alpha$-cuts we can suppose:

$$
x_{i j}^{L}(\alpha)=\alpha x_{i j}^{m}+(1-\alpha) x_{i j}^{l}, j=1, \ldots, n, i=1, \ldots, m
$$




$$
\begin{aligned}
& x_{i j}^{U}(\alpha)=\alpha x_{i j}^{m}+(1-\alpha) x_{i j}^{u}, \forall i, j \\
& y_{r j}^{L}(\alpha)=\alpha y_{r j}^{m}+(1-\alpha) y_{r j}^{l}, r=1, \ldots, s, j=1, \ldots, n \\
& y_{r_{j}}^{U}(\alpha)=\alpha y_{r j}^{m}+(1-\alpha) y_{r j}^{u}, \forall r, j \\
& z_{k j}^{L}(\alpha)=\alpha z_{k o}^{m}+(1-\alpha) z_{k o}^{l}, k=1, \ldots, t, j=1, \ldots, n \\
& z_{k j}^{U}(\alpha)=\alpha z_{k o}^{m}+(1-\alpha) z_{k o}^{u}, \forall k, j
\end{aligned}
$$

By the above assumption, the following model is obtained:

$$
\begin{aligned}
& \operatorname{Max} \sum_{r=1}^{s} u_{r}\left(y_{r o}^{L}(\alpha), y_{r o}^{U}(\alpha)\right)-\sum_{i=1}^{m} v_{i}\left(x_{i o}^{L}(\alpha), x_{i o}^{U}(\alpha)\right)-\sum_{k=1}^{t} \mu_{k}\left(z_{k o}^{L}(\alpha), z_{k o}^{U}(\alpha)\right) \\
& \sum_{r=1}^{s} u_{r}\left(y_{r j}^{L}(\alpha), y_{r j}^{U}(\alpha)\right)-\sum_{i=1}^{m} v_{i}\left(x_{i j}^{L}(\alpha), x_{i j}^{U}(\alpha)\right)-\sum_{k=1}^{t} \mu_{k}\left(z_{k j}^{L}(\alpha), z_{k j}^{U}(\alpha)\right) \leq 0, \quad j=1, \ldots, n \\
& u_{r} \geq 1, \quad r=1, \ldots, s, \quad v_{i} \geq 1, \quad i=1, \ldots, m, \quad \mu_{k}=1, \quad k=1, \ldots, t .
\end{aligned}
$$

Model (4) is an interval programming problem. We suppose the following variables:

$$
\begin{aligned}
& \tilde{x}_{i j} \in\left[x_{i j}^{L}(\alpha), x_{i j}^{U}(\alpha)\right], i=1, \ldots, m, \quad j=1, \ldots, n \\
& \tilde{y}_{r j} \in\left[y_{r j}^{L}(\alpha), y_{r j}^{U}(\alpha)\right], r=1, \ldots, s, \quad j=1, \ldots, n \\
& \tilde{z}_{k j} \in\left[z_{k j}^{L}(\alpha), z_{k j}^{U}(\alpha)\right], k=1, \ldots, t, \quad j=1, \ldots, n
\end{aligned}
$$

By substituting the new variables, (4) can be written as follows:

$$
\begin{aligned}
& \text { Max } \quad \sum_{r=1}^{s} u_{r} \tilde{y}_{r o}-\sum_{i=1}^{m} v_{i} \tilde{x}_{i o}-\sum_{k=1}^{t} \mu_{k} \tilde{z}_{k o} \\
& \text { s.t. } \sum_{r=1}^{s} u_{r} \tilde{y}_{r j}-\sum_{i=1}^{m} v_{i} \tilde{x}_{i j}-\sum_{k=1}^{t} \mu_{k} \tilde{z}_{k j} \leq 0, j=1, \ldots, n, \\
& x_{i j}^{L}(\alpha) \leq \tilde{x}_{i j} \leq x_{i j}^{U}(\alpha), \forall i, j, \\
& y_{r j}^{L}(\alpha) \leq \tilde{y}_{r j} \leq y_{r j}^{U}(\alpha), \forall r, j, \\
& z_{k j}^{L}(\alpha) \leq \tilde{z}_{k j} \leq z_{k j}^{U}(\alpha), \forall k, j \\
& u_{r} \leq 1, r=1, \ldots, s, v_{i} \leq 1, i=1, \ldots, m, \mu_{k}=1, k=1, \ldots, t .
\end{aligned}
$$

Model (5) is a nonlinear programming problem. In order to linearize this model, following substitutions are performed:

$$
\begin{aligned}
& \bar{x}_{i j}=v_{i} \tilde{x}_{i j}, i=1, \ldots, m, j=1, \ldots, n \\
& \bar{y}_{r j}=u_{r} \tilde{y}_{r j}, r=1, \ldots, s, j=1, \ldots, n \\
& \bar{z}_{k j}=\mu_{k} \tilde{z}_{k j}, k=1, \ldots, t, j=1, \ldots, n
\end{aligned}
$$

By these substitutions, (5) will become a linear problem as follows:

$$
\begin{aligned}
& \operatorname{Max} \sum_{r=1}^{s} \bar{y}_{r o}-\sum_{i=1}^{m} \bar{x}_{i o}-\sum_{k=1}^{t} \bar{z}_{k o} \\
& \sum_{r=1}^{s} \bar{y}_{r j}-\sum_{i=1}^{m} \bar{x}_{i j}-\sum_{k=1}^{t} \bar{z}_{k j} 0, j=1, \ldots, n, \\
& v_{i} x_{i j}^{L}(\alpha) \leq \bar{x}_{i j} \leq v_{i} x_{i j}^{U}(\alpha) \forall i, j, \\
& u_{r} y_{r j}^{L}(\alpha) \leq \bar{y}_{r j} \leq u_{r} y_{r j}^{U}(\alpha) \forall r, j, \\
& \mu_{k} z_{k j}^{L}(\alpha) \leq \bar{z}_{k j} \leq \mu_{k} z_{k j}^{U}(\alpha) \forall k, j \\
& u_{r} \geq 1, r=1, \ldots, s \\
& v_{i} \geq 1, i=1, \ldots, m \\
& \mu_{k}=1, \quad k=1, \ldots, t
\end{aligned}
$$

This model is equivalent to a parametric programming, while $\alpha \in(0,1]$ is a parameter. Thus, the fuzzy linear programming problem given by (3) can be equivalent to a crisp parametric linear programming problem. 


\section{Numerical Example}

In this section we want to illustrate the proposed model in assessing UK higher education institution. Two factors are considered as inputs that are triangular fuzzy numbers: general expenditure $\left(\tilde{x}_{1}\right)$ and equipment expenditure $\left(\tilde{x}_{2}\right)$, and three factors as outputs with triangular fuzzy numbers: undergraduate students $\left(\tilde{y}_{1}\right)$, postgraduate research $\left(\tilde{y}_{2}\right)$ and postgraduate teaching $\left(\tilde{y}_{3}\right)$, the flexible measure here is research income $\left(\tilde{z}_{1}\right)$ that is triangular fuzzy numbers. The status of research income for each university will be determined by the model. The data set consists of 10 universities as shown below.

Table 1. Data set for higher education institutions

\begin{tabular}{ccccccc}
\hline DMU & G. exp & E.exp & $\begin{array}{c}\text { UG } \\
\text { student }\end{array}$ & $\begin{array}{c}\text { PG } \\
\text { student }\end{array}$ & $\begin{array}{c}\text { PG } \\
\text { teaching }\end{array}$ & $\begin{array}{c}\text { Research } \\
\text { income }\end{array}$ \\
\hline 1 & $(528,450,606)$ & $(64,32,96)$ & $(145,78,212)$ & $(26,21,31)$ & $(0,0,0)$ & $(254,71,437)$ \\
2 & $(2605,441,4769)$ & $(301,236,366)$ & $(381,131,631)$ & $(70,21,119)$ & $(16,9,23)$ & $(1485,1091,1879)$ \\
3 & $(304,119,489)$ & $(23,19,27)$ & $(44,35,53)$ & $(6,2,10)$ & $(3,1,5)$ & $(45,10,80)$ \\
4 & $(1620,339,2901)$ & $(485,67,903)$ & $(287,201,373)$ & $(48,5,91)$ & $(0,0,0)$ & $(940,770,1110)$ \\
5 & $(490,63,917)$ & $(90,61,119)$ & $(91,45,137)$ & $(30,13,47)$ & $(8,2,14)$ & $(106,43,169)$ \\
6 & $(2675,769,4581)$ & $(467,284,1250)$ & $(352,60,644)$ & $(170,39,301)$ & $(4,2,6)$ & $(2967,2004,3930)$ \\
7 & $(422,337,507)$ & $(0,0,0)$ & $(70,43,97)$ & $(31,23,39)$ & $(12,11,13)$ & $(298,38,558)$ \\
8 & $(986,184,1788)$ & $(126,105,147)$ & $(203,33,373)$ & $(32,12,52)$ & $(0,0,0)$ & $(776,358,1194)$ \\
9 & $(523,68,978)$ & $(32,8,56)$ & $(60,30,90)$ & $(17,0,34)$ & $(0,0,0)$ & $(39,22,56)$ \\
10 & $(585,65,1105)$ & $(87,68,106)$ & $(80,52,108)$ & $(44,40,48)$ & $(17,2,32)$ & $(353,118,588)$ \\
\hline
\end{tabular}

Application of model (6) for the data shown in Table (1) at the different $\alpha$-cut such as $\alpha=0.9,1$ are shown in Table (2). The optimal values to $g_{1}$ indicate that either research income was considered as an input or output variable in the assessment model.

Table 2. Data set for higher education institutions

\begin{tabular}{cccccccccccc}
\hline$\alpha$-cut & DMU & 1 & 2 & 3 & 4 & 5 & 6 & 7 & 8 & 9 & 10 \\
\hline$\alpha=0.9$ & Effeciency & 0 & 1152.182 & 0 & 989.452 & 0 & 0 & 0 & 378.085 & 25.537 & 0 \\
& $g_{1}$ & 0 & 732.7889 & 0 & 340.991 & 0 & 0 & 0 & 301.402 & -131.855 & 0 \\
\hline$\alpha=1$ & Effeciency & 0 & 1931.593 & 73.15 & 1373.96 & 0 & 3038.09 & 0 & 708 & 161.962 & 168.801 \\
& $g_{1}$ & 0 & 813.091 & -32.92 & 437.25 & 0 & 2116.81 & 0 & 420.4 & -97.605 & 116.017 \\
\hline
\end{tabular}

\section{Conclusion}

In DEA models it is assumed that the status of each measure is clearly stated as an input or an output. However in some situations a performance measure can play input role for some DMUs and output role for others. In this paper we developed a fuzzy DEA model to calculate the relative efficiency of DMUs with flexible measures and evaluated that the flexible measure can use as an input or output. Using fuzzy data, the model is converted to a possibilistic programming problem. We use Saati and memariani method for converting this problem into a crisp linear programming based on $\alpha$-cut. In the Saati and memariani model they define suitable variables to solve. The substitutions of these variables make the model non-linear. By further suitable substitutions the model is linearized. Hence, by solving a linear programming problem for a given $\alpha$-cut, it is possible to generate a reliable and robust solution for possibilistic mathematical programming problems.

\section{References}

Amirteimoori, A., \& Emrouznejad, A. (2011). Flexible measures in production process. A DEA-based approach, 45, 63-74.

Amirteimoori, A., \& Khoshandam, L. (2011). Classifying inputs and outputs in Data Envelopment Analysis. Third Conference on Data Envelopment Analysis, 267.

Charnes, A., Cooper, W. W., \& Rhodes, E. (1978). Measuring the Efficiency of Decision Making Units. European Journal of Operational Research, 2, 429-444. http://dx.doi.org/10.1016/0377-2217(78)90138-8 
Cook, W. D., \& Zhu, J. (2007). Classifying inputs and outputs in DEA. European Journal of Operational Research, 180, 692-699. http://dx.doi.org/10.1016/j.ejor.2006.03.048

Guo, P., \& Tanaka, H. (2001). Fuzzy DEA: A perceptual Evaluation Method. Fuzzy Sets and Systems, 119, 149-160. http://dx.doi.org/10.1016/S0165-0114(99)00106-2

Maeda, Y., Entani, T., \& Tanaka, H. (1998). Fuzzy DEA with interval efficiency. 6 the European Congress on Intelligent Techniques and Soft Computing, 2, 1067-1071.

Saati, S., Memariani, A., \& Jahanshahloo, G. R. (2002). Efficiency Analysis and Ranking of DMUs with Fuzzy Data. Fuzzy Optimization and Decision Making, 1, 255-267. http://dx.doi.org/10.1023/A:1019648512614

Sengupta, J. K. (1992). A Fuzzy System Approach in Data Envelopment Analysis. Computers Math. Application, 24, 259-266. http://dx.doi.org/10.1016/0898-1221(92)90203-T

Shaocheng, T. (1994). Interval Number and Fuzzy Number Linear Programming. Fuzzy Sets and Systems, 66, 301-306. http://dx.doi.org/10.1016/0165-0114(94)90097-3

Tanaka, H., Ichihashi, H., \& Asai, K. (1984). A Formulation of Fuzzy Linear Programming Problems Based on Comparison of Fuzzy Numbers. Control and Cybernetics, 13, 186-194. 